\title{
Evolutionary Perspectives on Human Fungal Pathogens
}

\author{
John W. Taylor \\ University of California, Berkeley, California 94720-3102 \\ Correspondence: jtaylor@berkeley.edu
}

Owing to their small size and paucity of phenotypic characters, progress in the evolutionary biology of microbes in general, and human pathogenic fungi in particular, has been linked to a series of advances in DNA sequencing over the past quarter century. Phylogenetics was the first area to benefit, with the achievement of a basic understanding of fungal phylogeny. Population genetics was the next advance, finding cryptic species everywhere, and recombination in species previously thought to be asexual. Comparative genomics saw the next advance, in which variation in gene content and changes in gene family size were found to be important sources of variation. Fungal population genomics is showing that gene flow among closely related populations and species provides yet another source of adaptive, genetic variation. Now, two means to associate genetic variation with phenotypic variation, "reverse ecology" for adaptive phenotypes, and genome-wide association of any phenotype, are letting evolutionary biology make a profound contribution to molecular developmental biology of pathogenic fungi.

$T^{\mathrm{h}}$ he modern study of fungal evolution began with the access to nucleic acid variation enabled by the invention of the polymerase chain reaction (PCR) in 1988 (Saiki et al. 1988) because medically important fungi, apart from poisonous mushrooms, are small and provide too few morphological or physiological phenotypic characters for effective comparative evolutionary biology (Taylor et al. 2006). Their microscopic nature makes all the more remarkable Agustino Bassi's discovery in 1835 of the first microbe causing an animal disease, the Ascomycota, Beauveria bassiana, on silkworms (Porter 1973), a discovery in advance of Schwann's discovery of yeast cells in beer in 1837 (Schwann 1837), Pasteur's research on the microbiology of wine in 1866 (Pasteur 1866), and Koch's postulates on proving the microbial origin of disease in 1890 (Grimes 2006).

Perusal of Rippon's 1988 text on medical mycology demonstrates the challenges faced by evolutionary mycologists of that era (Rippon 1988). Rippon mentions many phylogenetic mysteries, including Coccidioides immitis, which today is known to be an Ascomycota despite never having revealed its sexual reproduction to mycologists. Rippon wrote, "Thus, we have a fungus (C. immitis) that has characteristics of a Zygomycete in its parasitic stage and is gymnoascaceous in its saprophytic stage. The problem will be fully settled only when the [sexual] state of C. immitis is found." There also are

Editors: Arturo Casadevall, Aaron P. Mitchell, Judith Berman, Kyung J. Kwon-Chung, John R. Perfect, and Joseph Heitman

Additional Perspectives on Human Fungal Pathogens available at www.perspectivesinmedicine.org

Copyright (C) 2015 Cold Spring Harbor Laboratory Press; all rights reserved; doi: 10.1101/cshperspect.a019588

Cite this article as Cold Spring Harb Perspect Med 2015;5:a019588 
J.W. Taylor

complete surprises, for example, the Ascomycota, Pneumocystis, is not even mentioned by Rippon, because it was considered to be a protist until nucleic acid sequence was obtained for its ribosomal RNA (Stringer et al. 1989).

The evolutionary biology of medically important fungi, along with fungi in general, has advanced on four fronts, each launched by an advance in access to DNA sequence variation: comparative phylogenetics launched by the aforementioned PCR, population genetics launched by the transition from manual to automated, Sanger, DNA sequencing, comparative genomics of fungi spurred by the human genome project, and population genomics launched by next-generation sequencing (NGS). This article will be organized to follow these four fronts to note the basic evolutionary biology that has been learned from each effort, with an emphasis on medically important fungi. Although the phylogenetic and population fields launched at different times, each continues to thrive, now relying on NGS for most applications. Recent reviews of medical mycology also contain material on the epidemiology (Pfaller and Diekema 2010), extent and origin (Heitman 2011), and evolution (Taylor 2006) of fungal pathogens.

\section{MOLECULAR PHYLOGENETICS}

Mycology followed the lead of bacteriologists in using ribosomal RNA sequences for molecular phylogenetics because kingdom-wide primers could be designed to match ultraconserved ribosomal regions that flanked the phylogenetically informative, variable regions (White et al. 1990). Protein coding genes were added to the studies, principally proteins associated with DNA replication, ribosomal proteins, and elongation factors, as well as an ATP subunit (James et al. 2006). The rDNA regions continue to be useful as fungal, molecular barcodes (Schoch et al. 2012) and for ecological studies in which fungi are identified from DNA isolated from environmental samples (Adams et al. 2013).

Phylogenetics of medically important fungi had to be studied in the context of all fungi, because fungi capable of parasitizing hu- mans come from throughout the fungal kingdom, especially those pathogens seen in patients whose immune system had been compromised through disease or suppressed to avoid rejection of transplanted bone marrow or solid organs. In fact, there probably has been no more profound effect on the field of medical mycology, and the study of fungal molecular phylogenetics in general, than the recognition in 1987 that infections with certain fungi were AIDS-defining diseases (CDC 1987). These opportunistic fungal pathogens included species of Candida, Cryptococcus, and Pneumocystis, in addition to the long-recognized, systemic pathogens, Coccidioides and Histoplasma, and were joined shortly by Penicillium marneffii. In 2000, the Atlas of Clinical Fungi (de Hoog et al. 2000) contained 314 additional species, almost all of them opportunistic pathogens and none more important to patients in transplant or cancer therapy than Aspergillus species, principally Aspergillus fumigatus.

The most complete molecular phylogeny of fungi has come from the AFTOL project with publications on the entire kingdom (James et al. 2006) and individual phyla (see Mycologia, 2006, Vol. 98, No. 6). Most animal parasitic fungi are Ascomycota and two clades of filamentous Ascomycota (Pezizomycotina) are particularly rich in pathogens, the Hypocreales and the Onygenales (Fig. 1). The Hypocreales is home to parasites of insects, including Bassi's silkworm pathogen, the Zombie Ant fungus, Ophiocordyceps unilataeralis, expert manipulator of host behavior (Evans et al. 2011; Hughes et al. 2011), and the human pathogen, Pseudallescheria. The Onygenales embrace the human and animal dermatophytes, including Trichophyton species, as well as fungi causing systemic disease of mammals, that is, the systemic pathogens, Coccidioides, Histoplasma, Blastomyces, and Paracoccidioides. These dangerous, BSL3 containment pathogens and their fellow Eurotiomycetes, Aspergillus and Penicillium, are joined by fungi from other clades of filamentous Ascomycota, including Exophiala, Sporothrix, and Neotestudina species. The most important genus of fungal pathogens in North America, the yeast Candida, represents the Saccharo- 


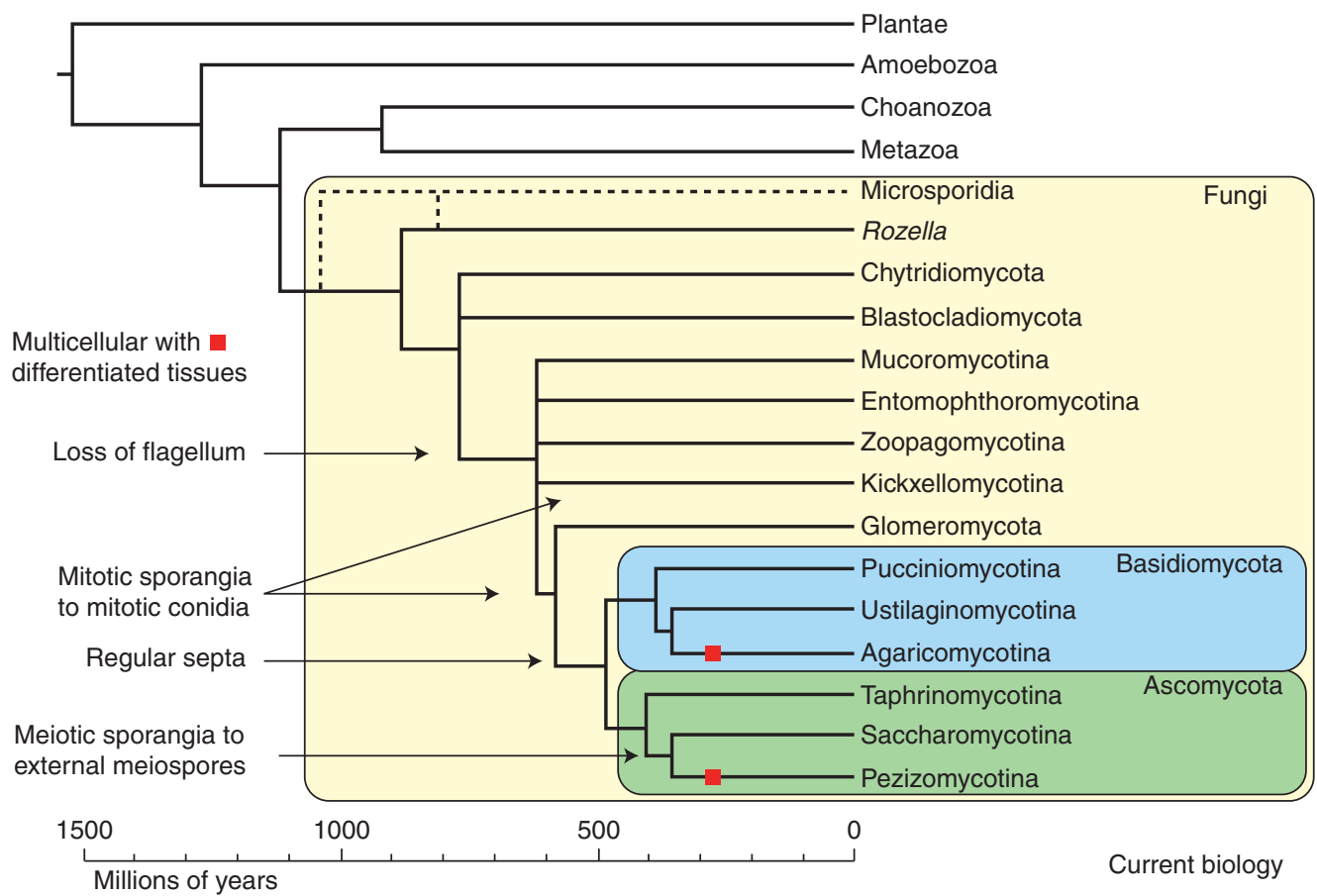

Figure 1. Phylogeny of fungi. Most human pathogenic fungi are Ascomycota, with Candida species in Saccharomycotina, Pneumocystis in Taphrinomycotina, and the Onygenales clade of systemic pathogens and dermatophytes in Pezizomycotina. Basidiomycotina also harbors important pathogens, Cryptococcus and Trichosporon species in Agaricomycotina and Malassezia species in Ustilaginomycotina. (From Stajich et al. 2009; reprinted, with permission, from the authors. Based on approaches and phylogenies in James et al. 2006 and Taylor and Berbee 2006.)

mycotina and the third Ascomycota subphylum, Taphrinomycotina, harbors the aforementioned Pneumocystis.

Apart from Ascomycota, the Basidiomycota harbors the next most important agents of human disease, Cryptococcus species that can be opportunistic pathogens of immense importance to AIDS patients (i.e., Cryptococcus neoformans), or emerging pathogens of otherwise healthy hosts (i.e., Cryptococcus gattii). In the same subphylum of Basidiomycota, Agaricomycotina, is found Trichosporon, agent of dermatomycoses, and in the subphylum, Ustilaginomycotina, is found Malassezia, skin commensal associated with dandruff. The human, opportunistic pathogens Mucor, Rhizopus, and Basidiobolus are found in clades of zygomycetes, and at the very base of the Kingdom Fungi emerge the Microsporidia, a species that also causes human disease (Didier and Weiss 2011).
Other basal, fungal phyla harbor animal pathogens (i.e., Blastocaldiomycota and Chytridiomycota) (home to Batrachochytrium dendrobatidis, scourge of amphibians), but no human pathogens. Outside the fungal kingdom, several groups traditionally studied by mycologists harbor species capable of causing severe human disease (e.g., the phylogenetically close Mesomycetozoea [Icthyosporae]) contains Rhinosporidium (Mendoza et al. 2002) and the distant Oomycota harbors Pythium insidiosum (Mendoza and Newton 2005).

Examination of phylogenies of these fungi, which can be fit to a geological timescale (albeit with significant uncertainly) (Berbee and Taylor 2010), has led to formulation of general hypotheses about the evolution of fungi pathogens. Among them is the observation that adaptation to parasitize amoebae may have prepared fungi to live in amoebae-like host cells devoted to 
J.W. Taylor

immunological response (Steenbergen et al. 2001) and that the kingdom-wide scarcity of thermotolerant fungi may have been a selective force in the evolution of endothermy in mammals and birds (Casadevall 2005; Robert and Casadevall 2009; Taylor and Gurr 2014).

\section{POPULATION GENETICS}

Just as PCR combined with manual DNA sequencing made comparative phylogenomics possible, PCR combined with semiautomated DNA sequencing, whether by gels or gel-filled capillaries, made population genetics possible. The ability to study tens to hundreds of isolates from one morphological species discovered hidden genetic variation that led to fundamental changes in how we recognize fungal species and how we view fungal reproduction.

Biological species recognition, the gold standard for species recognition in plants and animals, had little impact on fungal systematics in general and medical mycology in particular because it required experimental mating. To be sure, biological species recognition was practiced with model fungal organisms, among them, the Ascomycota Saccharomyces cerevisiae and Neurospora crassa, and the Basidiomycota, Schizophyllum commune, Heterobasidion annosum and Armellaria mellea; however, explicitly excluded were the ca. $20 \%$ of fungi for which sexual reproduction had not been observed. Included in this group are many medically important fungi (e.g., Candida albicans, A. fumigatus, Coccidioides immitis, and Sporothrix schenckii), as well as human pathogens for which sexual reproduction is difficult to achieve in the laboratory (e.g., Histoplasma or Blastomyces). Like countries that have leapt from inadequate landline telephone service directly to cell phones, mycology went directly from morphological species recognition to phylogenetic species recognition, which led to the discovery that almost all morphological species of medically important fungi harbored more than one phylogenetic species, typically termed "cryptic species," because they had not been recognized morphologically. Thus, C. albicans also had Candida dubliniensis (Sullivan et al. 1995), Coccidioides immitis also had C. posadasii (Fisher et al. 2002), C. neoformans also had C. grubii, albeit described as a variety (Franzot et al. 1999), Paracoccidioides brasiliensis also had P. lutzi (Matute et al. 2006; Teixeira et al. 2014), Blastomyces dermatidis also had $B$. gilchristii (Brown et al. 2013), and Histoplasma capsulatum had at least six additional species (Kasuga et al. 2003), as well as a new group recently found to be associated with cats (Balajee et al. 2013). Even model, biological species (e.g., S. cerevisiae and $N$. crassa), were found to have additional, phylogenetic species, among which mating was still possible (e.g., Saccharomyces paradoxus [Martini 1989] or Neurospora perkinsii [Villalta et al. 2009]). It is unusual to find a medically important, morphological species that has just one phylogenetic species. A. fumigatus is one example of a globally distributed phylogenetic species, despite being studied by two different groups, who used different collections of isolates and different variable DNA regions (Paoletti et al. 2005; Pringle et al. 2005; Rydholm et al. 2006). This opportunistic pathogen is ubiquitous in soils and, as a thermophile, in compost. Perhaps it has been able to maintain a global population by associating with the spread of humans and their compost.

A fair concern about phylogenetic species, as compared to morphological species, is there any clinical relevance (Latge 2013)? The welldifferentiated, cryptic species, C. albicans and C. dubliniensis showed differences in virulence (Gilfillan et al. 1998). Within C. albicans in China, it has been reported that different genotypes associate with different phenotypes of disease presentation and antifungal resistance (Bai 2014), and that his association can involve clades of pathogenic strains that are geographically distinct (Ge et al. 2012). European C. albicans has also shown association between genotype and antifungal resistance, as well as cellsurface repeats, but not pathogenicity (Odds 2010). Very recently, phylogeny was combined with antifungal susceptibility testing for nearly 10,000 yeast strains in nearly 20 species, again showing a correlation between susceptibility and phylogeny (Schmalreck et al. 2014). With filamentous Ascomytcota, even the more weak- 
ly differentiated cryptic species (e.g., C. immitis and C. posadasii), showed variation in salt tolerance (Fisher et al. 2002). Differences in virulence are hypothesized for cryptic species in Paracoccidioides (Teixeira et al. 2013) and Blastomyces (Meece et al. 2013) and morphological differences and differences in cultivation are known for unnamed species-level clades of $H$. capsulatum (Edwards and Rappleye 2011). In most of these cases, morphological correlates of phylogenetic species were not observed until it was possible to sort strains into the various cryptic species, only then were the phenotypic differences recognized. For example, with Sporothrix species, after phylogenetic species and populations had been identified, tests of antifungal drug susceptibility found associations between genotype and phenotype that could be used to predict therapeutic outcomes (Rodrigues et al. 2014).

These studies of fungal species recognition, revealing multiple, genetically isolated taxa, often occupying geographically distinct ranges, provided evidence to refute the hypothesis that microbes, because of unlimited dispersal, show no endemism and have global, panmictic populations (Finlay 2002). With the exception of $A$. fumigatus and the dermatophytes, studies of medically important fungi show that "everything is not everywhere” (Taylor 2006).

Recombination is instrumental in promoting adaptation, as has been experimentally demonstrated with $S$. cerevisiae (Goddard et al. 2005), and recombining and clonal reproduction can be distinguished using the same data that enable phylogenetic species recognition. However, population tests for reproductive mode can be made only after the phylogenetic species have been recognized because they are confounded if isolates from different, genetically isolated groups are mixed. Beginning with C. immitis (Burt et al. 1996), evidence for recombination was found in medically important species in which clonal conidia were obvious and sexual reproduction had not been observed. This unexpected observation challenged the notion that Coccidioides and, by inference, the other 20\% of fungi that lacked the morphology of sexual reproduction, were limited to clonal re- production. Subsequent studies of $C$. posadasii (Fisher et al. 2000), a related Onygenaceae, Paracoccidiides brasiliensis (Matute et al. 2006), and Eurotiales, A. fumigatus (Paoletti et al. 2005; Pringle et al. 2005) and P. marneffii (Henk et al. 2012) have also found evidence for recombination in collections of wild isolates from single phylogenetic species. Evidence that the mechanism of recombination is sexual comes from observations of a balance of mating types in wild populations of Coccidioides (Fraser et al. 2007; Mandel et al. 2007), A. fumigatus (Rydholm et al. 2006) and P. marneffii (Henk et al. 2012), the presence of intact mating loci, and, in the case of $A$. fumigatus, confirmation of sexual reproduction by successful laboratory matings (O'Gorman et al. 2009). These fungi, Coccidioides, Aspergillus, and Penicillium, are haploid and outbreeding (heterothallic, to use the mycological jargon), making interpretation of their reproductive behavior fairly straightforward. Although, in the case of $P$. marneffii, very low variation among interbreeding groups of wild isolates made detection of recombination more difficult (Henk et al. 2012). However, two of the most important pathogens, C. albicans and C. neoformans, are typically diploid and unraveling their reproductive modes has been more challenging, as discussed below.

The potential for reproduction in fungi goes beyond simple sexual recombination and clonal spread. Most fungi capable of sexual recombination have at least two mating alleles (termed idiomorphs because of their extreme divergence) in the population, which can promote outbreeding and restrict inbreeding. Some of the most important medically important fungi are exceptional in that natural isolates are either diploids with two copies of the same allele, as in C. albicans, or haploids with a population of isolates having just one mating allele, as in $C$. neoformans. Although it is possible that each species has unsampled populations of haploid individuals with a balance of mating alleles from which the animal- or human-associated strains emerged, skewed by some environmental factor in their distribution in ploidy and mating type, but it does not seem likely given the attention paid to these pathogens. Recent studies 
J.W. Taylor

show that fungi with identical mating alleles, or haploids derived from diploids by aneuploidy (Hickman et al.2013), have the potential to mate and recombine in both C. albicans (Alby et al. 2009) and C. neoformans var. grubii (Roach et al. 2014). A key question is whether or not these fungi, which clearly can spread clonally in nature and can be mated in the lab, also recombine in nature. Population genetic tests were used to report recombination in C. albicans in early studies (Gräser et al. 1996), and have been supported recently in a study of nearly 1400 isolates (Odds et al. 2007). Other Candida species, including C. parapsilosis and its close relatives, $C$. metapsilosis and C. orthopsilosis, have also been investigated, with the finding that $C$. parapsilosis and C. metapsilosis isolates have just one mating idiomorph, whereas C. orthopsilosis has a balance of both (Sai et al. 2011). By inference, one might expect that only $C$. orthopsilosis would be recombining in nature, as demonstrated by the discovery of natural hybridization among strains from two of its populations (Pryszcz et al. 2014). However, comparison of genomes of just a few C. parapsilosis strains also showed genetic variation consistent with recombination and independent adaptation to an environmental stress, arsenite (Pryszcz et al. 2013).

The mechanism of mating between diploid C. albicans is closely tied to pathogenesis through a developmental change necessary for both processes, the switch from white cells to opaque cells. Avery thorough review of the topic (Pujol and Soll 2011) concludes that the C. albicans population structure supports recombination as well as clonality, but notes three possible sources of the recombined genotypes. The first source would be sexual reproduction involving diploids, tetraploids, and meiosis; in support of this option, they note that a closely related species, C. lusitaniae, is sexual (Reedy et al. 2009; Butler 2010). The second source would be parasexuality involving diploids, tetraploids, and aneuploidy reductions, as has been demonstrated in the laboratory. Here, a close relative of C. albicans, C. tropicalis, which also requires a phenotypic switch to initiate mating (Porman et al. 2011), has a parasexual cycle involving diploid cells mating to form tet- raploids, which then reduce to the diploid state by aneuploidy (Seervai et al. 2013). The third possible explanation would be recombination that persists from an ancestral, sexual population. The difficulty of tracking the source by mimicking the natural environment in the laboratory was recently demonstrated when wild C. tropicalis strains, few of which would switch from white to opaque in the laboratory, were stimulated to do so by providing $\mathrm{N}$-acetylglucosamine as the carbon source (Xie et al. 2012). This study was followed by a similar discovery in $C$. albicans, in which an increase in the carbon dioxide concentration in addition to providing $\mathrm{N}$-acetylglucosamine stimulated switching in wild isolates (Xie et al. 2013). These studies show that the environment is critical to producing natural behavior, and caution against using laboratory observation to limit the range of possible natural behaviors.

As noted above, a similar reproductive situation exists with the important Basidiomycota yeast pathogen, C. neoformans. Here, population genetic analyses detected recombination in wild isolates collected from populations having both mating idiomorphs, or just a single one (Saul et al. 2008). This phenomenon can be explained from laboratory research showing that mating and meiosis can occur between nonisogenic strains of the same mating idiomorph (Lin et al. 2005). More recently, aneuploidy has been shown to result from matings between partners having the same idiomorph, as well as those with the two, different idiomorphs, with the interesting twist that these aneuploidy progeny show more phenotypic variation than those arising from meiosis alone (Ni et al. 2013).

To make matters even more interesting, two phylogenetic species of C. neoformans var. grubii coexist in Botswana, one has a global distribution with almost all individuals having just one mating allele, the other is restricted to Botswana and has an even distribution of mating alleles (Litvintseva et al. 2003). Analyses showed recombination, but not between the two phylogenetic species. One interpretation is that the global phylogenetic species emerged from Africa (Litvintseva et al. 2003) but another 
is that the global phylogenetic species, strongly biased toward one mating idiomorph, emerged from some other location and dispersed to Africa. Studies of natural isolates of another Cryptococcus species, C. gattii have also detected evidence of recombination in nature (Ngamskulrungroj et al. 2009).

As plastic as reproduction seems in the medically important yeasts, the model fungus, S. cerevisiae, is even more flexible in its reproductive cycle. Most commonly, it inbreeds with siblings of the opposite mating type in the ascus, and, less commonly, it switches mating alleles to mate with itself when there is no partner of the opposite mating type and, least commonly, it outbreeds. In spite of all the inbreeding and selfing, it has a recombining population structure (Tsai et al. 2008). There is a genetic effect of all of this inbreeding and selfing in that linkage blocks are at least three to nine times larger in $S$. cerevisiae than in what is thought to be an obligate outbreeder, N. crassa (Liti et al. 2009; Ellison et al. 2011a).

In only a few cases have population genetic studies failed to find recombination in fungi, and even in medically important fungi. Included in this select group are fungi that are transmitted from host to host, rather than being acquired from the environment. For example, no evidence of recombination and only evidence of clonal spread has been found in the athlete's foot fungus, Trichophyton rubrum (Gräser et al. 1999, 2006) or the histoplasmosis of horses and donkeys (Kasuga et al. 2003). Both of these cases demonstrate that clonal lineages of pathogenic fungi can emerge from recombining populations, as has been noted for both of these cases. Detecting cases in which clonal lineages have emerged from recombining populations is difficult and requires thorough collecting from different geographic areas in both nature and the clinic. A good example is provided by the recent C. gattii outbreak in the Pacific Coast of British Columbia, Canada and points further south in the United States. The initial interpretation of the source of the outbreak strains as recombinants from clonal lineages in Australia and North America was based on the outbreak strains and a small sample of environmental isolates (Fraser et al. 2005). The interpretation changed to clonal genotypes emerging from a recombining population in South America when sampling enlarged to include that continent (Hagen et al. 2013).

The need to sample has risen in prominence as the cost of DNA sequencing has plummeted; in fact, the limiting resource in population genetics has become the collection of isolates. The studies mentioned above on C. neoformans (Litvintseva et al. 2003), A. fumigatus (Pringle et al. 2005), C. immitis (Fisher et al. 2002), N. crassa (Ellison et al. 2011a), or S. cerevisiae (Liti et al. 2009) all had tens to hundreds of isolates collected from throughout their ranges and, with the exception of $C$. immitis, at least as many environmental as clinical isolates. Population genetic studies are essential for understanding reproductive mode in nature, but do not specify the mechanism of recombination and can be difficult to apply where collections of wild isolates are limiting. Here, laboratory studies are needed, sometimes finding intact, meiotic genes in fungi that have yet to reveal their sexual mechanisms, as recently reviewed (Butler 2010).

Idiomorphs, the mating loci that are too strongly diverged to deserve the name "allele," can have interesting evolutionary histories. Idiomorphs and mating regions diverge because they are prevented from recombining and they enlarge when additional regions of somatic chromosomes become trapped in the zones blocked from recombining. C. neoformans displays this trait (Heitman et al. 2013; Heitman 2014) and larger nonrecombining regions, approaching entire chromosomes, are seen in some Neurospora species (Menkis et al. 2008, 2010; Ellison et al. 2011a). Although the divergence is similar to animal sex chromosomes, the degeneration of one ideomorph relative to the other does not occur, presumably because the fungi must exist for at least a part of their life cycles as haploids. In Ascomycota, the mating locus itself can be introgressed from one species to another, as seen in some plant pathogenic fungi (Inderbitzin et al. 2005) and Neurospora (Strandberg et al. 2010; Sun et al. 2012b). It also has been recently shown that even large idio- 
J.W. Taylor

morphic regions of suppressed recombination, as seen in Cryptococcus, can be subject to recombination via gene conversion (Sun et al. 2012a).

Even the naming of fungi has been affected by the mixture of clonal and recombining reproductive systems. For nearly 150 years, Ascomycota and some Basidiomycota could have more than one name, one for the sexual state and one for each clonal state. The same access to nucleic acid variation that promoted evolutionary biology of fungi made the system of dual nomenclature unnecessary because sexual and clonal states of the same species have the same, distinctive genomes (Taylor 2011). As of January 1, 2013, each fungus must have only one name (McNeill and Turland 2011). The challenge now is to choose among the names attached to each fungus. For example, the genus Candida was applied to all morphologically undistinguished, clonal Ascomycota yeasts. Now the name can be retained for one species, logically, C. albicans, and the phylogenetically distant species should gain new names that emphasize evolutionary differences. Similar reasoning can be applied to species of Cryptococcus, the name that was applied to all morphologically undistinguished Basidiomycota yeasts, and even Aspergillus, where half-a-dozen clades with distinct sexual morphology as are distant from each other as they are from Penicillium (Pitt and Taylor 2014).

\section{COMPARATIVE GENOMICS}

Nowhere is comparative genomics better practiced than with fungi because of the plethora of sequenced, fungal genomes (cf., F1000, genome.jgi.doe.gov/pages/fungi-1000-projects .jsf; Fungidb, fungidb.org/fungidb; GOLD, www.genomesonline.org). Beginning with $S$. cerevisiae and relatives (Kellis et al. 2003), followed shortly by filamentous Aspergillus species (Galagan et al. 2005), many fungi, including the important fungal pathogens, have been compared to their relatives, sometimes with just a few other strains or species but increasingly in larger projects. The "low hanging fruit," to use a dated genomics phrase, has proved to be discoveries of gene gain, gene loss, and gene duplica- tion, processes that can lead to gene family expansion or contraction. These sources of genetic variation often have been correlated with important phenotypes in pathogenic fungi.

Experiments designed to detect chromosome duplication were conducted with yeast using strains in which one of a pair of duplicated genes had been deleted. Robust growth was restored when the region containing the remaining gene spontaneously duplicated and rapid sequencing of these strains showed that the duplications were large (Koszul et al. 2004). A reasonable inference is that all regions of fungal genomes are being duplicated all the time, but that these duplications rarely confer any selective advantage and cells or nuclei harboring them are lost. In those rare cases in which the duplication or loss does confer a fitness advantage, it is retained. The many cases in which gene duplications have been discovered through comparative genomics in fungi, to be discussed below, support this inference.

Much has been written about the fate of duplicated genes and how they can evolve to take on different functions. However, a comparison of genomes throughout the Ascomycota, including Saccharomycotina, Pezizomycotina, and Taphrinomycotina, found that duplicated genes evolved to different modes of regulation, but not different functions (Wapinski et al. 2007). In the same study, it was noted that genes associated with signal reception, transport, cell walls, and stress responses were more often duplicated than those essential for viability and growth, and whose gene products are found in nuclei and nucleoli, endoplasmic reticulum, and the Golgi apparatus, or mitochondria. Given that expansion to new environments, whether physical in the case of geographical range extensions, or biological in the case of host range expansion, involves adaptation to new stresses, this result seems logical.

The largest concentration of fungi that cause disease of otherwise healthy humans is in the Onygenales, and this group has been a focus of comparative genomic studies concerned with gene duplications. In fact, the first report of gene duplication in this group predates genomics, and came from studies of en- 
zymes that digest animal protein, the metalloprotease M36 family of fungalysins in the genera Trichophyton and Microsporum (Jousson et al. 2004).

When genomes of $C$. immitis and C. posadasii became available, they were compared to genomes from a close, nonpathogenic relative, Uncinocarpus reesii, a more distantly related pathogen (Histoplasma), and several even more distant, nonpathogenic Ascomycota in the Eurotiomycetes (Aspergillus) and Sordariomycetes (Fusarium, Neurospora). The most striking findings were that genes coding for enzymes involved in the deconstruction of plant cell walls were absent from all the pathogens and $U$. reesii, whereas they were common in the nonpathogens, and that genes coding for proteases (i.e., subtilisin $\mathrm{N}$, peptidase S8, and peptidase M35), had significantly higher copy numbers in the two Coccidioides species and $U$. reesii than in the nonpathogens or H. capsulatum (Sharpton et al. 2009). The authors inferred that the ancestral substrate of filamentous Ascomycota was plant carbon and that the ancestor of the Onygenales adapted to use other sources of nutrition. In the case of the ancestor of the Coccidioides clade, including $U$. reesii, animal protein became the substrate of choice.

As genomes of dermatophyte Onygenales became available, comparative genomics continued, focusing on secondary metabolite gene clusters. Here, the dermatophytes have large numbers of these biosynthetic clusters compared to the systemic pathogens $C$. immitis and $H$. capsulatum, leading the authors to suggest that the systemic parasite had lost the clusters as they became more adapted to the full force of the host immune response (Burmester et al. 2011).

Continued study of the fungal proteases confirmed the disparity in gene number between pathogens and saprobes (Muszewska et al. 2011). These studies then turned to a phylogenetic, likelihood approach, leading reports of positive natural selection acting on genes and on specific amino acid positions for both M35 and M36 families in the dermatophytes and for the M35 family in the Coccidioides species ( $\mathrm{Li}$ et al. 2012; Li and Zhang 2014). A similar ap- proach had previously been used to detect selection on Coccidioides antigens and the ribosomal repeat region (Johannesson et al. 2004, 2005).

When genomes of three Paracoccidioides strains became available, they were added to the analyses, again finding a loss of genes involved in metabolizing carbohydrates in these species (Desjardins et al. 2011). These authors also experimented with the growth of $U$. reesii on 190 carbon substrates, including carbohydrates and proteins. They found that this close relative of Coccidioides has a preference for growth on protein over carbohydrate, as predicted from the comparative genomic comparisons described above.

Although distantly related to Onygenales, comparative genomics of the zygomycete genus, Rhizopus, also revealed expansion of protease gene families, in this case those for aspartic proteases and subtilase (Ma et al. 2009). This study also detected an expansion of genes in the ergosterol synthesis pathway, including the genes whose product, ERG11, is the target of azole antifungal drugs.

Comparative genomics has also been an active pursuit with Candida species. An early comparison among six Candida species and ten other yeasts found significant expansions in genes associated with cell walls, secretion, and molecular transport, all of them suggesting a role in virulence (Butler et al. 2009). Another comparative genomic study between C. albicans and its more weakly pathogenic relative, $C$. dubliniensis, found elaboration of gene families of transcription factors and transmembrane proteins in C. albicans and a loss of genes regulating filamentous growth in C. dubliniensis (Jackson et al. 2009). More recently, comparison of genomes of Candida glabrata and relatives, which are closer relatives of $S$. cerevisiae than C. albicans, found that adhesin genes, considered important for pathogenicity, had expanded in the ancestor of both pathogenic and nonpathogenic species (Gabaldón et al. 2013). This result indicates that these fungi were preadapted to pathogenicity, echoing aforementioned thinking about thermotolerance and life within amoebae being necessary preadaptations for the pathogen life- 
J.W. Taylor

style. Comparative genomics can also have a very practical side. A search for 55 genes essential to C. albicans or A. fumigatus found that ten were also found in other pathogens and that six of these were absent from humans; four of these are now the subject of pharmaceutical research (Abadio et al. 2011).

Switching to Basidiomycota, comparative genomics has been applied to very closely related genotypes of the important pathogen, $C$. neoformans. Variants of $C$. neoformans strain H99 were assembled that differ in melanization, mating capacity, and virulence in animal models as a result of their having been passaged in vivo and in vitro. These strains also showed variation in environmental and pharmaceutical stress response as well as urease production. Comparisons of their genomes found indels in the passaged strains, and these could be associated, in a mating population study, with the phenotypes of reduced mating and melanization (Janbon et al. 2014). The authors also found minor chromosome length variants, which were more common near chromosome ends. Interestingly, these genetic variants may not have phenotypes because the genes involved were either of unknown function or also found elsewhere in the genome, and these genetic differences did not associate with any phenotype. This study shows the power of comparative genomics to detect effects of evolution over short time periods, and also provides a clear means to ensure that different labs, or even different workers in the same lab, are truly working on the same strains.

Also in Basidiomycota, genomes of the agent of atopic eczema, Malassezia sympodialis and that associated with dandruff, Malassezia globosa, have been compared with the expected finding in these lipophilic yeasts of no genes for fatty acid synthesis and few genes for lipid biosynthesis, and the unexpected result that there were few genes known to mediate adhesion or biofilm production in organisms that seemingly must adhere to their hosts (Gioti et al. 2013). Given the role that fungi must play in allergies, an exciting aspect of the study was a focus on antigenic proteins, one of which, Mala S 7, has history of gene expansion.

\section{POPULATION GENOMICS}

It was the latest advance in genomic sequencing, NGS, which moved genomics from comparisons of one individual per species to comparisons of many individuals within species, or population genomics. Population genomics will obviously advance the field of fungal evolution, but will also advance fungal molecular and developmental biology. This latter advance comes in two varieties, one to find adaptive genes and another to associate genetic variation with phenotypic variation, that is, to find the genes behind any phenotype, virulence included. Comparison of individuals in a population is also revealing new sources of genetic variation that were impossible to detect by comparing single representatives of more distantly related taxa. Examples of this nascent field, which come from studies of plant and animal pathogens as well as some model fungi, show that genome regions move between species by hybridization and introgression more commonly that previously thought and that the retention of specific regions is because of positive natural selection for adaptive genes that lie in the regions. A recent review describes some of these studies (Gladieux et al. 2014) and another discusses the genetic mechanisms behind hybridization and introgression (Morales and Dujon 2012).

Coccidioides reaped the benefits of prior population genetic research by being chosen, in the era of Sanger sequencing, for population genomics of more than a dozen individuals from the two species, C. immitis and C. posadasii (Neafsey et al. 2010). Evolutionarily, the most exciting finding was introgression of a surprisingly large fraction (7\%) of the genome between the two species. One region moving into $C$. immitis from $C$. posadasii contained a metalloprotease gene (mep 4) located near one edge of one of the introgressed regions. This gene was hypothesized to be the one responsible for sweeping the region between species. However, subsequent transcription studies found that mep 4 was not up-regulated in the shift from the environmental, hyphal form to the parasitic, endosporulating spherule form. Instead, a small, 
unnamed gene that is located right between mep4 and the edge of the introgressed region, CIMG_00509, is strongly up-regulated in the shift from environmental to pathogen phenotype (Whiston et al. 2012). The gene product of this gene is predicted to be secreted and the hypothesis about adaptive genes has shifted from mep 4 to this gene, a hypothesis that awaits validation experiments.

Human pathogens excepted, the most important fungal pathogen of animals must be the Chytridiomycota, $B$. dendrobatidis, which threatens an astounding 30\% of the world's amphibian species. Two recent population genomic studies have reached very similar conclusions about the evolution of this pathogen (Farrer et al. 2013; Rosenblum et al. 2013). They find that one clade in the species complex, termed the Global Panzootic Lineage, is responsible for the amphibian decline. This lineage is not simply a clonal expansion from an as yet undiscovered ancestral population, but a complex clade harboring significant genetic variation. Contributing to the diversity is chromosome copy number variation, cryptic recombination within and among isolates, large, unrecombined regions that contain genes known to contribute to pathogenicity in other fungi, and genes under directional selection. Among the genes under directional selection are proteases, as has been discussed for Onygenales.

Chromosome duplication in pathogenetic lineages is not restricted to $B$. dendrobatidis. Chromosome duplication also has been implicated in azole antifungal resistance in C. albicans, in which it has been most carefully studied. Recently, it has been shown that aneuploids develop in C. albicans via a tetraploid intermediate and subsequent unequal DNA segregation (Harrison et al. 2014). These aneuploids were seen to develop in response to azole antifungals, indicating that aneuploids arise because of antifungal treatment during the infection process and are retained through selection for the increased azole resistance that they confer. Chromosome polymorphisms and copy number variation have also been researched in other pathogenic yeasts, including C. glabrata (Muller et al. 2009) and C. neoformans (Morrow and Fraser 2013).
In addition to animal pathogenic fungi, population genomics is beginning to be applied to plant pathogens. A recent, thorough study of the wheat pathogen Mycosphaerella graminicola and closely related strains from wild grasses, between which much ancestral variation has been preserved, found that almost no neutral, nonsynonymous mutations between the two populations, implying very strong selection on the pathogen's genes, which included those coding for secreted proteins and effectors that fungi use to parasitize plants (Stukenbrock et al. 2011).

Fungal population genomics is also practiced with model fungi, exemplified in a recent population genomic study that compared genomes chosen to span the natural variation of S. cerevisiae and S. paradoxus, but biased toward European isolates of both species- and humanassociated isolates of S. cerevisiae (Bergström et al. 2014). The most startling result is that the ratio of gene gains, losses, and duplications as compared to SNPs is far higher in S. cerevisiae than $S$. paradoxus. Phenotypically, there is also more variation in $S$. cerevisiae than $S$. paradoxus. The genes showing copy number variation in $S$. cerevisiae produce proteins whose functions indicate an interaction with the environment (e.g., sugar transport and metabolism, cell adhesion and cell-to-cell flocculation, and metal transport and metabolism). For genes involved in resistance to arsenic (a source of stress previously noted for Candida species [Pryszcz et al. 2013]), the European clade had higher copy numbers, consistent with adaptation to geographically different environments. Saccharomyces species are among the few in which population genomic studies could include hundreds to thousands of individuals combined with high-throughput phenotype analysis and hypothesis testing by gene deletion or allele swaps. The medically important yeasts, C. albican and C. neoformans are two others. We can only hope.

The filamentous, model Ascomycota, N. crassa, also has been the subject of population genomic analysis. As with Coccidioides and Saccharomyces, previous research on population genetics and phylogenetic species recognition 
J.W. Taylor

paved the way for genomic studies. Analysis of the genomes of 50 individuals from what was thought to be one population based on concordance of four gene genealogies found seven populations, fortunately, two of them, from Louisiana and the Caribbean, happened to be well sampled (Ellison et al. 2011a). Comparison of the genomes from these two populations, between which only $10 \%$ of ancestral polymorphism had been lost, revealed two regions of exceptional divergence (Fig. 2). Although the regions were strongly diverged between the populations, they were quite similar within populations, consistent with their having entered the populations by hybridization and introgression from an as-yet-unsampled source, and then having been swept through the populations. If this scenario were true, there should be genes in the regions that confer an adaptive advantage in response to some parameter differing between the environments experienced by the two populations. Given the presence of a cold-stress RNA helicase in one region, and a cold-stress prefoldin in the other, it was hypothesized that these genes provided adaptation to the $10^{\circ} \mathrm{C}$ lower temperature experienced by the Louisiana strains as compared to their Caribbean neighbors. Fitness experiments with wild-type and gene-deletion mutants at high and low temperatures failed to disprove the hypothesis (or validated it, to use current parlance) that these regions swept through the Louisiana population, driven by selection for adaptation to what, for N. crassa, is an unusually cold environment (Ellison et al. 2011a). This approach is the reverse of the ecology practiced with large organisms (i.e., plants or animals), in which environmental factors and adaptive phenotypes are easier to identify and in which one can then predict which genes are likely to be responsible for the phenotype; for that reason, the microbial approach has been termed "reverse ecology."

Just as studies of population genetics and phylogenetic species recognition set the stage for population genomic research, population genomics sets the stage for studies that have the potential to revolutionize the genetics of human pathogenic fungi by enabling genomewide association studies (GWAS). Examples from two fungi, one a plant pathogen and one a saprobe, show the potential of this approach.

One attribute that makes both of these examples of interest to medical mycology is that relatively few strains need to be phenotyped. In each study, fewer than 100, even as few as two dozen, were phenotyped as compared to the thousands of strains that must be phenotyped in a mutational screen or gene-deletion library or the 500 commonly used in a mating population quantitative trait locus (QTL) study. A second attribute is that the association is to a single gene, or even part of a single gene, owing

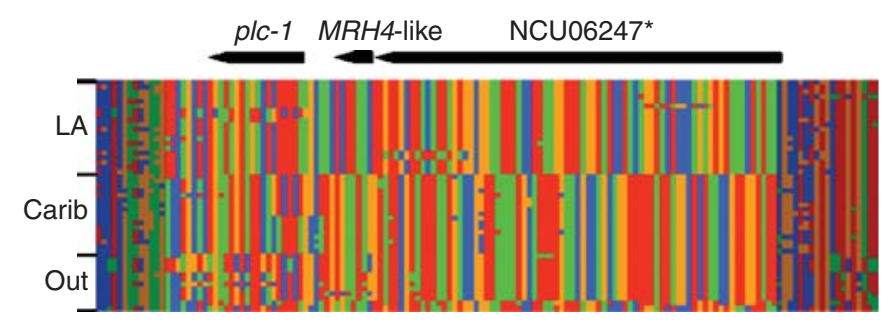

Figure 2. Aligned N. crassa genomes showing a region with extreme divergence between Louisiana and Caribbean populations and relative uniformity within populations, consistent with its origin by hybridization and introgression from a more diverged source. Strains for which MRH4-like (a dead box RNA helicase) had been deleted showed reduced growth at low temperature, consistent with the hypothesis that this gene drove a selective sweep in the northern, Louisiana population (Ellison et al. 2011a). Rows are individual genomes from Louisiana (LA), Caribbean (Carib), and related (Out) populations. Columns are polymorphic nucleotide positions. Each color signifies one of the four nucleotides. Deletion of genes coding for phospholipase C (plc-1) or an unidentified protein found in mitochondria (NUC06247*) had no significant effect on growth at low temperature. (From Ellison et al. 2011a; reprinted, with permission, from the author.) 


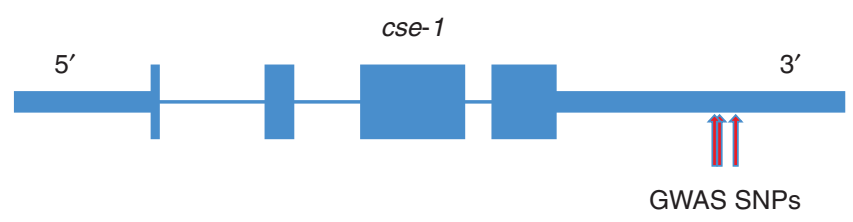

Figure 3. N. crassa calcium sensor-1 gene, cse-1. The three SNPs (arrows) are shown that associated strongly with variation in the phenotype of germling signaling in a genome-wide association study (GWAS) (Palma-Guerrero et al. 2013). Although there were SNPs in the exons, they did not associate, demonstrating the precision that can be achieved using GWAS in a small, panmictic population of an oblilgately outbreeding fungus. Introns are thin lines, exons are thick lines, and $5^{\prime}$ and $3^{\prime}$ untranslated regions are of intermediate thickness. (From PalmaGuerrero et al. 2013; reprinted, with permission, from the author.)

to the effect of recombination from a multitude of mating events in a wild population as compared to the one mating in a QTL crossing study (Fig. 3).

The first GWAS of a fungus was for the fungal pathogen of forest trees, $H$. annosum (Dalman et al. 2013). Here, just 23 genomes were used to associate genetic variation with the phenotypic variation of virulence on spruce and pine hosts. The analysis found seven genes that associated with virulence, four of which were known to be virulence factors in other plant pathogenic fungi and three new ones. Hypotheses about these genes await validation.

At nearly the same time, GWAS was applied to a complex morphological and physiological trait in N. crassa (Palma-Guerrero et al. 2013). Having first used population genomics to recognize a truly panmictic population with no detectable population structure (Ellison et al. 2011a), the researchers assessed variation among ca. 100 strains for the trait of germling fusion. In this phenomenon, conidia form pairs that then communicate so that their germination tubes grow toward each other to fuse before they initiate a large colony. Using a sample of 24 strains that spanned the range of variation found in all 100 , the authors found strong association between the trait and one gene (cse-1) that codes for a calcium-sensitive protein involved in signaling in mammals and yeast (Fig. 3). Knowledge of two proteins that interact with this gene in mammals and yeast increased to three the number of putative genes involved in the trait. By relaxing the false discovery rate for genes associating with the trait in the GWAS, another
18 putative genes were added to the total. Tests of the hypotheses that the genes associated with the phenotype were truly involved ensued, using wild-type and gene-deletion mutants. These tests validated the association of $c s e-1$, the two interacting proteins and six of the 18 genes identified by relaxing the false-positive threshold. In addition to finding nine new genes involved in the trait, three of them were the first to be found whose deletion positively affected the trait, rather than decreasing it. In addition to Candida species, other pathogenic fungi with tremendous potential for GWAS include the Botswana population of C. neoformans var. grubii, the South American population of C. gattii, and populations of both Coccidioides species.

\section{THE FUTURE}

Advances in DNA sequencing, beginning with PCR, and moving through improvements in Sanger sequencing and now NGS of various types have brought increasingly sophisticated evolutionary studies to fungi. It seems inevitable that sequencing costs will continue to fall and that all evolutionary studies will then employ complete sequences for all isolates. Phylogenomics is already replacing phylogenetics, and the challenge is to select the set of genes that best address questions about particular divergences (Lopez-Giraldez and Townsend 2011). Barcoding, presently focused on the hypervariable ITS region, will be supplanted by genome sequencing to allow researchers to pick regions of genomic variation appropriate for their evolutionary or ecological questions. Species and populations 
J.W. Taylor

will be recognized by population genomics, which will replace phylogenetic species recognition or multilocus sequence typing. Once populations have been recognized, the most exciting application of NGS will become routine (i.e., finding the genes responsible for specific phenotypes). Where researchers want to let evolution identify the adaptive phenotypes, reverse ecology will be used to find the adaptive genes. More commonly, researchers will want to choose the phenotype of interest, and, here, GWAS will be the approach. The challenge to GWAS will be to increase the number of individuals from 100 to 1000 or 10,000 , as now is common in GWAS for humans. The challenge for both GWAS and reverse ecology will be testing the hypotheses about genes responsible for phenotypes in fungi outside the few, well-studied model organisms.

\section{ACKNOWLEDGMENTS}

J.W.T. acknowledges the support of National Science Foundation (NSF) Grant DBI-10-46115 and NSF Grant DEB-12-57528.

\section{REFERENCES}

Abadio AKR, Kioshima ES, Teixeira MM, Martins NF, Maigret B, Felipe MSS. 2011. Comparative genomics allowed the identification of drug targets against human fungal pathogens. BMC Genomics 12: 75.

Adams RI, Miletto M, Taylor JW, Bruns TD. 2013. Dispersal in microbes: Fungi in indoor air are dominated by outdoor air and show dispersal limitation at short distances. ISME J 7: 1262-1273.

Alby K, Schaefer D, Bennett RJ. 2009. Homothallic and heterothallic mating in the opportunistic pathogen Candida albicans. Nature 460: 890-893.

Bai F. 2014. Association of genotypes with infection types and antifungal susceptibilities in Candida albicans as revealed by recent molecular typing strategies. Mycology 5: $1-9$.

Balajee SA, Hurst SF, Chang LS, Miles M, Beeler E, Hale C, Kasuga T, Benedict K, Chiller T, Lindsley MD. 2013. Multilocus sequence typing of Histoplasma capsulatum in formalin-fixed paraffin-embedded tissues from cats living in non-endemic regions reveals a new phylogenetic clade. Med Mycol 51: 345-351.

Berbee ML, Taylor JW. 2010. Dating the molecular clock in fungi-How close are we? Fungal Biol Rev 24: 1-16.

Bergström A, Simpson JT, Salinas F, Barre B, Parts L, Zia A, Ba ANN, Moses AM, Louis EJ, Mustonen V, et al. 2014. A high-definition view of functional genetic variation from natural yeast genomes. Mol Biol Evol 31: 872-888.

Brown EM, McTaggart LR, Zhang SX, Low DE, Stevens DA, Richardson SE. 2013. Phylogenetic analysis reveals a cryptic species Blastomyces gilchristii, sp. Nov. within the human pathogenic fungus Blastomyces dermatitidis. Plos ONE 8: e59237.

Burmester A, Shelest E, Glockner G, Heddergott C, Schindler S, Staib P, Heidel A, Felder M, Petzold A, Szafranski K, et al. 2011. Comparative and functional genomics provide insights into the pathogenicity of dermatophytic fungi. Genome Biol 12: R7.

Burt A, Carter DA, Koenig GL, White TJ, Taylor JW. 1996. Molecular markers reveal cryptic sex in the human pathogen Coccidioides immitis. Proc Natl Acad Sci 93: 770773.

Butler G. 2010. Fungal sex and pathogenesis. Clin Microbiol Rev 23: 140-159.

Butler G, Rasmussen MD, Lin MF, Santos MAS, Sakthikumar S, Munro CA, Rheinbay E, Grabherr M, Forche A, Reedy JL, et al. 2009. Evolution of pathogenicity and sexual reproduction in eight Candida genomes. Nature 459: 657-662.

Casadevall A. 2005. Fungal virulence, vertebrate endothermy, and dinosaur extinction: Is there a connection? Fungal Genet Biol 42: 98-106.

CDC. 1987. Revision of the CDC surveillance case definition for acquired immunodeficiency syndrome. MMWR 36: S1-S15.

Dalman K, Himmelstrand K, Olson A, Lind M, Brandstrom-Durling M, Stenlid J. 2013. A genome-wide association study identifies genomic regions for virulence in the non-model organism Heterobasidion annosum s.s. Plos ONE 8: e53525.

de Hoog GS, Guarro J, Gené J, Figueras MJ. 2000. Atlas of clinical fungi, 2nd ed. Centraalbureau voor Schimmelcultures, Utrecht, The Netherlands.

Desjardins CA, Champion MD, Holder JW, Muszewska A, Goldberg J, Bailao AM, Brigido MM, da Silva Ferreira ME, Garcia AM, Grynberg M, et al. 2011. Comparative genomic analysis of human fungal pathogens causing paracoccidioidomycosis. Plos Genet 7: e1002345.

Didier ES, Weiss LM. 2011. Microsporidiosis: Not just in AIDS patients. Curr Opin Infect Dis 24: 490-495.

Edwards JA, Rappleye CA. 2011. Histoplasma mechanisms of pathogenesis - One portfolio doesn't fit all. FEMS Microbiol Lett 324: 1-9.

Ellison CE, Hall C, Kowbel D, Welch J, Brem RB, Glass NL, Taylor JW. 2011a. Population genomics and local adaptation in wild isolates of a model microbial eukaryote. Proc Natl Acad Sci 108: 2831-2836.

Ellison CE, Stajich JE, Jacobson DJ, Lapidus A, Foster B, Aerts A, Riley R, Lindquist EA, Grigoriev IV, Taylor JW. $2011 \mathrm{~b}$. Massive changes in genome architecture accompany the transition to self-fertility in the filamentous fungus Neurospora tetrasperma. Genetics 189: 55-69.

Evans HC, Elliot SL, Hughes DP. 2011. Hidden diversity behind the zombie-ant fungus Ophiocordyceps unilateralis: Four new species described from carpenter ants in Minas Gerais, Brazil. Plos ONE 6: e17024. 
Evolution of Human Fungal Pathogens

Farrer RA, Henk DA, Garner TWJ, Balloux F, Woodhams DC, Fisher MC. 2013. Chromosomal copy number variation, selection and uneven rates of recombination reveal cryptic genome diversity linked to pathogenicity. Plos Genet 9: e1003703.

Finlay BJ. 2002. Global dispersal of free-living microbial eukaryote species. Science 296: 1061-1063.

Fisher MC, Koenig GL, White TJ, Taylor JW. 2000. Pathogenic clones versus environmentally driven population increase: Analysis of an epidemic of the human fungal pathogen Coccidioides immitis. J Clin Microbiol 38: 807 813.

Fisher MC, Koenig GL, White TJ, Taylor JW. 2002. Molecular and phenotypic description of Coccidioides posadasii sp. nov., previously recognized as the non-California population of Coccidioides immitis. Mycologia 94: 73-84.

Franzot SP, Salkin IF, Casadevall A. 1999. Cryptococcus neoformans var grubii: Separate varietal status for Cryptococcus neoformans serotype A isolates. J Clin Microbiol 37: 838-840.

Fraser JA, Giles SS, Wenink EC, Geunes-Boyer SG, Wright JR, Diezmann S, Allen A, Stajich JE, Dietrich FS, Perfect JR, et al. 2005. Same-sex mating and the origin of the Vancouver Island Cryptococcus gattii outbreak. Nature 437: $1360-1364$

Fraser JA, Stajich JE, Tarcha EJ, Cole GT, Inglis DO, Sil A, Heitman J. 2007. Evolution of the mating type locus: Insights gained from the dimorphic primary fungal pathogens Histoplasma capsulatum, Coccidioides immitis, and Coccidioides posadasii. Eukaryot Cell 6: 622-629.

Gabaldón T, Martin T, Marcet-Houben M, Durrens P, Bolotin-Fukuhara M, Lespinet O, Arnaise S, Boisnard S, Aguileta G, Atanasova R, et al. 2013. Comparative genomics of emerging pathogens in the Candida glabrata clade. BMC Genomics 14: 623 .

Galagan JE, Calvo SE, Cuomo C, Ma LJ, Wortman JR, Batzoglou S, Lee SI, Basturkmen M, Spevak CC, Clutterbuck J, et al. 2005. Sequencing of Aspergillus nidulans and comparative analysis with A. fumigatus and A. oryzae. Nature 438: 1105-1115.

Ge S-H, Xie J, Xu J, Li J, Li D-M, Zong L-L, Zheng Y-C, Bai F-Y. 2012. Prevalence of specific and phylogenetically closely related genotypes in the population of Candida albicans associated with genital candidiasis in China. Fungal Genet Biol 49: 86-93.

Gilfillan GD, Sullivan DJ, Haynes K, Parkinson T, Coleman DC, Gow NAR. 1998. Candida dubliniensis: Phylogeny and putative virulence factors. Microbiology 144: 829838.

Gioti A, Nystedt B, Li W, Xu J, Andersson A, Averette AF, Muench K, Wang X, Kappauf C, Kingsbury JM, et al. 2013. Genomic insights into the atopic eczema-associated skin commensal yeast Malassezia sympodialis. MBio 4: e00572-12.

Gladieux P, Ropars J, Badouin H, Branca A, Aguileta G, De Vienne DM, De La Vega RCR, Branco S, Giraud T. 2014. Fungal evolutionary genomics provides insight into the mechanisms of adaptive divergence in eukaryotes. $\mathrm{Mol}$ Ecol 23: 753-773.

Goddard MR, Godfray HCJ, Burt A. 2005. Sex increases the efficacy of natural selection in experimental yeast populations. Nature 434: 636-640.
Gräser Y, Volovsek M, Arrington J, Schonian G, Presber W, Mitchell TG, Vilgalys R. 1996. Molecular markers reveal that population structure of the human pathogen Candida albicans exhibits both clonality and recombination. Proc Natl Acad Sci 93: 12473-12477.

Gräser Y, Kühnisch J, Presber W. 1999. Molecular markers reveal exclusively clonal reproduction in Trichophyton rubrum. J Clin Microbiol 37: 3713-3717.

Gräser Y, De Hoog S, Summerbell RC. 2006. Dermatophytes: Recognizing species of clonal fungi. Med Mycol 44: 199-209.

Grimes DJ. 2006. Koch's postulates-Then and now. Microbe 1: 223-228.

Hagen F, Ceresini PC, Polacheck I, Ma H, van Nieuwerburgh F, Gabaldon T, Kagan S, Pursall ER, Hoogveld HL, van Iersel LJJ, et al. 2013. Ancient dispersal of the human fungal pathogen Cryptococcus gattii from the Amazon rainforest. Plos ONE 8: e71148.

Harrison BD, Hashemi J, Bibi M, Pulver R, Bavli D, Nahmias Y, Wellington M, Sapiro G, Berman J. 2014. A tetraploid intermediate precedes aneuploid formation in yeasts $\mathrm{ex}$ posed to fluconazole. Plos Biol 12: 1001815.

Heitman J. 2011. Microbial pathogens in the fungal kingdom. Fungal Biol Rev 25: 48-60.

Heitman J. 2014. Evolutionary genomics of the Cryptococcus species complex. Mycoses 57: 16-16.

Heitman J, Sun S, James TY. 2013. Evolution of fungal sexual reproduction. Mycologia 105: 1-27.

Henk DA, Shahar-Golan R, Devi KR, Boyce KJ, Zhan N, Fedorova ND, Nierman WC, Hsueh P-R, Yuen K-Y, Sieu TPM, et al. 2012. Clonality despite sex: The evolution of host-associated sexual neighborhoods in the pathogenic fungus Penicillium marneffei. Plos Pathog 8: e1002851.

Hickman MA, Zeng GS, Forche A, Hirakawa MP, Abbey D, Harrison BD, Wang YM, Su CH, Bennett RJ, Wang Y, et al. 2013. The "obligate diploid" Candida albicans forms mating-competent haploids. Nature 494: 55-59.

Hughes D, Andersen S, Hywel-Jones N, Himaman W, Billen J, Boomsma J. 2011. Behavioral mechanisms and morphological symptoms of zombie ants dying from fungal infection. BMC Ecol 11: 13.

Inderbitzin P, Harkness J, Turgeon BG, Berbee ML. 2005. Lateral transfer of mating system in Stemphylium. Proc Natl Acad Sci 102: 11390-11395.

Jackson AP, Gamble JA, Yeomans T, Moran GP, Saunders D, Harris D, Aslett M, Barrell JF, Butler G, Citiulo F, et al. 2009. Comparative genomics of the fungal pathogens Candida dubliniensis and Candida albicans. Genome Res 19: 2231-2244.

James TY, Kauff F, Schoch CL, Matheny PB, Hofstetter V, Cox CJ, Celio G, Gueidan C, Fraker E, Miadlikowska J, et al. 2006. Reconstructing the early evolution of Fungi using a six-gene phylogeny. Nature 443: 818-822.

Janbon G, Ormerod KL, Paulet D, Byrnes EJ III, Yadav V, Chatterjee G, Mullapudi N, Hon C-C, Billmyre RB, Brunel F, et al. 2014. Analysis of the genome and transcriptome of Cryptococcus neoformans var. grubii reveals complex RNA expression and microevolution leading to virulence attenuation. Plos Genet 10: e1004261. 
J.W. Taylor

Johannesson H, Vidal P, Guarro J, Herr RA, Cole GT, Taylor JW. 2004. Positive directional selection in the proline-rich antigen (PRA) gene among the human pathogenic fungi Coccidioides immitis, C. posadasii and their closest relatives. Mol Biol Evol 21: 1134-1145.

Johannesson H, Townsend JP, Hung CY, Cole GT, Taylor JW. 2005. Concerted evolution in the repeats of an immunomodulating cell surface protein, SOWgp, of the human pathogenic fungi Coccidioides immitis and C. posadasii. Genetics 171: 109-117.

Jousson O, Lechenne B, Bontems O, Capoccia S, Mignon B, Barblan J, Quadroni M, Monod M. 2004. Multiplication of an ancestral gene encoding secreted fungalysin preceded species differentiation in the dermatophytes Trichophyton and Microsporum. Microbiology 150: 301-310.

Kasuga T, White TJ, Koenig G, McEwen J, Restrepo A, Castaneda E, Lacaz CD, Heins-Vaccari EM, De Freitas RS, Zancope-Oliveira RM, et al. 2003. Phylogeography of the fungal pathogen Histoplasma capsulatum. Mol Ecol 12: 3383-3401.

Kellis M, Patterson N, Endrizzi M, Birren B, Lander ES. 2003. Sequencing and comparison of yeast species to identify genes and regulatory elements. Nature 423: 241-254.

Koszul R, Caburet S, Dujon B, Fischer G. 2004. Eucaryotic genome evolution through the spontaneous duplication of large chromosomal segments. EMBO J 23: 234-243.

Latge JP. 2013. Oh, to be new. N Engl J Med 369: 1464-1466.

Li J, Yu L, Tian YM, Zhang KQ. 2012. Molecular evolution of the deuterolysin (M35) family genes in Coccidioides. Plos ONE 7: e31536.

Li J, Zhang K-Q. 2014. Independent expansion of zincin metalloproteinases in onygenales fungi may be associated with their pathogenicity. Plos ONE 9: e90225.

Lin XR, Hull CM, Heitman J. 2005. Sexual reproduction between partners of the same mating type in Cryptococcus neoformans. Nature 434: 1017-1021.

Liti G, Carter DM, Moses AM, Warringer J, Parts L, James SA, Davey RP, Roberts IN, Burt A, Koufopanou V, et al. 2009. Population genomics of domestic and wild yeasts. Nature 458: 337-341.

Litvintseva AP, Marra RE, Nielsen K, Heitman J, Vilgalys R, Mitchell TG. 2003. Evidence of sexual recombination among Cryptococcus neoformans serotype A isolates in sub-Saharan Africa. Eukaryot Cell 2: 1162-1168.

Lopez-Giraldez F, Townsend JP. 2011. PhyDesign: An online application for profiling phylogenetic informativeness. BMC Evol Biol 11: 152.

Ma L-J, Ibrahim AS, Skory C, Grabherr MG, Burger G, Butler M, Elias M, Idnurm A, Lang BF, Sone T, et al. 2009. Genomic analysis of the basal lineage fungus Rhizopus oryzae reveals a whole-genome duplication. Plos Genet 5: e1000549.

Mandel MA, Barker BM, Kroken S, Rounsley SD, Orbach MJ. 2007. Genomic and population analyses of the mating type loci in Coccidioides species reveal evidence for sexual reproduction and gene acquisition. Eukaryot Cell 6: $1189-1199$.

Martini AV. 1989. Saccharomyces paradoxus comb nov., a newly separated species of the Saccharomyces sensu stric- to complex based upon nDNA/nDNA homologies. Syst Appl Microbiol 12: 179-182.

Matute DR, McEwen JG, Montes BA, San-Blas G, Bagagli E, Rauscher JT, Restrepo A, Morais F, Nino-Vega G, Taylor JW. 2006. Cryptic speciation and recombination in the fungus Paracoccidioides brasiliensis as revealed by gene genealogies. Mol Biol Evol 23: 65-73.

McNeill J, Turland NJ. 2011. Major changes to the Code of Nomenclature-Melbourne, July 2011. Taxon 60: 14951497.

Meece JK, Anderson JL, Gruszka S, Sloss BL, Sullivan B, Reed KD. 2013. Variation in clinical phenotype of human infection among genetic groups of Blastomyces dermatitidis. J Infect Dis 207: 814-822.

Mendoza L, Newton JC. 2005. Immunology and immunotherapy of the infections caused by Pythium insidiosum. Med Mycol 43: 477-486.

Mendoza L, Taylor JW, Ajello L. 2002. The class Mesomycetozoea: A heterogeneous group of microorganisms at the animal-fungal boundary. Annu Rev Microbiol 56: 315344.

Menkis A, Jacobson DJ, Gustafsson T, Johannesson H. 2008. The mating-type chromosome in the filamentous ascomycete Neurospora tetrasperma represents a model for early evolution of sex chromosomes. Plos Genet 4: e1000030.

Menkis A, Whittle CA, Johannesson H. 2010. Gene genealogies indicates abundant gene conversions and independent evolutionary histories of the mating-type chromosomes in the evolutionary history of Neurospora tetrasperma. BMC Evol Biol 10: 234.

Morales L, Dujon B. 2012. Evolutionary role of interspecies hybridization and genetic exchanges in yeasts. Microbiol Mol Biol Rev 76: 721-739.

Morrow CA, Fraser JA. 2013. Ploidy variation as an adaptive mechanism in human pathogenic fungi. Semin Cell Dev Biol 24: 339-346.

Muller H, Thierry A, Coppee J-Y, Gouyette C, Hennequin C, Sismeiro O, Talla E, Dujon B, Fairhead C. 2009. Genomic polymorphism in the population of Candida glabrata: Gene copy-number variation and chromosomal translocations. Fungal Genet Biol 46: 264-276.

Muszewska A, Taylor JW, Szczesny P, Grynberg M. 2011. Independent subtilases expansions in fungi associated with animals. Mol Biol Evol 28: 3395-3404.

Neafsey DE, Barker BM, Sharpton TJ, Stajich JE, Park DJ, Whiston E, Hung CY, McMahan C, White J, Sykes S, et al. 2010. Population genomic sequencing of Coccidioides fungi reveals recent hybridization and transposon control. Genome Res 20: 938-946.

Ngamskulrungroj P, Gilgado F, Faganello J, Litvintseva AP, Leal AL, Tsui KM, Mitchell TG, Vainstein MH, Meyer W. 2009. Genetic diversity of the Cryptococcus species complex suggests that Cryptococcus gattii deserves to have varieties. Plos ONE 4: e5862.

Ni M, Feretzaki M, Li W, Floyd-Averette A, Mieczkowski P, Dietrich FS, Heitman J. 2013. Unisexual and heterosexual meiotic reproduction generate aneuploidy and phenotypic diversity de novo in the yeast Cryptococcus neoformans. Plos Biol 11: 1001653. 
Odds FC. 2010. Molecular phylogenetics and epidemiology of Candida albicans. Future Microbiol 5: 67-79.

Odds FC, Bougnoux M-E, Shaw DJ, Bain JM, Davidson AD, Diogo D, Jacobsen MD, Lecomte M, Li S-Y, Tavanti A, et al. 2007. Molecular phylogenetics of Candida albicans. Eukaryot Cell 6: 1041-1052.

O'Gorman CM, Fuller HT, Dyer PS. 2009. Discovery of a sexual cycle in the opportunistic fungal pathogen Aspergillus fumigatus. Nature 457: 471-474.

Palma-Guerrero J, Hall CR, Kowbel D, Welch J, Taylor JW, Brem RB, Glass NL. 2013. Genome wide association identifies novel loci involved in fungal communication. Plos Genet 9: e1003669.

Paoletti M, Rydholm C, Schwier EU, Anderson MJ, Szakacs G, Lutzoni F, Debeaupuis JP, Latge JP, Denning DW, Dyer PS. 2005. Evidence for sexuality in the opportunistic fungal pathogen Aspergillus fumigatus. Curr Biol 15: $1242-$ 1248.

Pasteur L. 1866. Études sur le vin, ses maladies, causes qui les provoquent, procédés nouveaux pour le conserver et pour le vieillir [Studies on wine, its diseases and their causes, and new processes to conserve and age wine]. Imprimerie Impériale, V. Masson et Fils, Paris.

Pfaller MA, Diekema DJ. 2010. Epidemiology of invasive mycoses in North America. Crit Rev Microbiol 36: 1-53.

Pitt JI, Taylor JW. 2014. Aspergillus, its sexual states, and the new International Code of Nomenclature. Mycologia pii: 14-060 doi: 10.3852/14-060.

Porman AM, Alby K, Hirakawa MP, Bennett RJ. 2011. Discovery of a phenotypic switch regulating sexual mating in the opportunistic fungal pathogen Candida tropicalis. Proc Natl Acad Sci 108: 21158-21163.

Porter JR. 1973. Agostino Bassi bicentennial (1773-1973). Bacteriol Rev 37: 284-288.

Pringle A, Baker DM, Platt JL, Wares JP, Latge JP, Taylor JW. 2005. Cryptic speciation in the cosmopolitan and clonal human pathogenic fungus Aspergillus fumigatus. Evolution 59: 1886-1899.

Pryszcz LP, Nemeth T, Gacser A, Gabaldón T. 2013. Unexpected genomic variability in clinical and environmental strains of the pathogenic yeast Candida parapsilosis. Genome Biol Evol 5: 2382-2392.

Pryszcz LP, Németh T, Gácser A, Gabaldón T. 2014. Genome comparison of Candida orthopsilosis clinical strains reveals the existence of hybrids between two distinct subspecies. Genome Biol Evol 6: 1069-1078.

Pujol C, Soll DR. 2011. Genome plasticity in Candida albicans. In Genome plasticity and infectious diseases (ed. Hacker J, Dobrindt U, Kurth R), pp. 303-325. American Society for Microbiology, Washington, DC.

Reedy JL, Floyd AM, Heitman J. 2009. Mechanistic plasticity of sexual reproduction and meiosis in the Candida pathogenic species complex. Curr Biol 19: 891-899.

Rippon JW. 1988. Medical mycology: The pathogenic fungi and the pathogenic Actinomycetes. W.B. Saunders, Philadelphia.

Roach KC, Feretzaki M, Sun S, Heitman J. 2014. Unisexual reproduction. In Advances in genetics (ed. Friedmann T, Dunlap JC, Goodwin SF), Vol. 85, pp. 255-305.
Robert VA, Casadevall A. 2009. Vertebrate endothermy restricts most fungi as potential pathogens. J Infect Dis 200: $1623-1626$.

Rodrigues AM, de Hoog GS, Pires DD, Brihante RSN, Sidrim JJD, Gadelha MF, Colombo AL, de Camargo ZP. 2014. Genetic diversity and antifungal susceptibility profiles in causative agents of sporotrichosis. BMC Infect Dis 14: 219.

Rosenblum EB, James TY, Zamudio KR, Poorten TJ, Ilut D, Rodriguez D, Eastman JM, Richards-Hrdlicka K, Joneson S, Jenkinson TS, et al. 2013. Complex history of the amphibian-killing chytrid fungus revealed with genome resequencing data. Proc Natl Acad Sci 110: 9385-9390.

Rydholm C, Szakacs G, Lutzoni F. 2006. Low genetic variation and no detectable population structure in Aspergillus fumigatus compared to closely related Neosartorya species. Eukaryot Cell 5: 650-657.

Sai S, Holland LM, McGee CF, Lynch DB, Butler G. 2011. Evolution of mating within the Candida parapsilosis species group. Eukaryot Cell 10: 578-587.

Saiki RK, Gelfand DH, Stoffel S, Scharf SJ, Higuchi R, Horn GT, Mullis KB, Erlich H. 1988. Primer-directed enzymatic amplification of DNA with a thermostable DNA polymerase. Science 239: 487-491.

Saul N, Krockenberger M, Carter D. 2008. Evidence of recombination in mixed-mating-type and $\alpha$-only populations of Cryptococcus gattii sourced from single Eucalyptus tree hollows. Eukaryot Cell 7: 727-734.

Schmalreck AF, Lackner M, Becker K, Fegeler W, Czaika V, Ulmer H, Lass-Flori C. 2014. Phylogenetic relationships matter: Antifungal susceptibility among clinically relevant yeasts. Antimicrob Agents Chemother 58: 15751585.

Schoch CL, Seifert KA, Huhndorf S, Robert V, Spouge JL, Levesque CA, Chen W, Consortium FB. 2012. Nuclear ribosomal internal transcribed spacer (ITS) region as a universal DNA barcode marker for Fungi. Proc Natl Acad Sci 109: 6241-6246.

Schwann T. 1837. Vorläufige Mittheilung, bettreffend Versuche über die Weingährung und Fäulniss [Preliminary communication concerning experiments on the making and putrefaction of wine]. Ann Phys Chem 41: 184-193.

Seervai RNH, Jones SK Jr, Hirakawa MP, Porman AM, Bennett RJ. 2013. Eukaryot Cell 12: 1629-1640.

Sharpton TJ, Stajich JE, Rounsley SD, Gardner MJ, Wortman JR, Jordar VS, Maiti R, Kodira CD, Neafsey DE, Zeng $\mathrm{QD}$, et al. 2009. Comparative genomic analyses of the human fungal pathogens Coccidioides and their relatives. Genome Res 19: 1722-1731.

Stajich JE, Berbee ML, Blackwell M, Hibbett DS, James TY, Spatafora JW, Taylor JW. 2009. The fungi. Curr Biol 19: R840-R845.

Steenbergen JN, Shuman HA, Casadevall A. 2001. Cryptococcus neoformans interactions with amoebae suggest an explanation for its virulence and intracellular pathogenic strategy in macrophages. Proc Natl Acad Sci 98: 1524515250 .

Strandberg R, Nygren K, Menkis A, James TY, Wik L, Stajich JE, Johannesson H. 2010. Conflict between reproductive gene trees and species phylogeny among heterothallic and pseudohomothallic members of the filamentous as- 
J.W. Taylor

comycete genus Neurospora. Fungal Genet Biol 47: 869878.

Stringer SL, Stringer JR, Blase MA, Walzer PD, Cushion MT 1989. Pneumocystis carinii: Sequence from ribosomal RNA implies a close relationship with fungi. Exp Parasitol 68: 450-461.

Stukenbrock EH, Bataillon T, Dutheil JY, Hansen TT, Li RQ, Zala M, McDonald BA, Wang J, Schierup MH. 2011. The making of a new pathogen: Insights from comparative population genomics of the domesticated wheat pathogen Mycosphaerella graminicola and its wild sister species. Genome Res 21: 2157-2166.

Sullivan DJ, Westerneng TJ, Haynes KA, Bennett DE, Coleman DC. 1995. Candida dubliniensis sp. Nov.: Phenotypic and molecular characterization of a novel species associated with oral candidosis in HIV-infected individuals. Microbiology 141: 1507-1521.

Sun S, Hsueh Y-P, Heitman J. 2012a. Gene conversion occurs within the mating-type locus of Cryptococcus neoformans during sexual reproduction. Plos Genet 8: e1002810.

Sun Y, Corcoran P, Menkis A, Whittle CA, Andersson SGE, Johannesson H. 2012b. Large-scale introgression shapes the evolution of the mating-type chromosomes of the filamentous ascomycete Neurospora tetrasperma. Plos Genet 8: e1002820.

Taylor JW. 2006. Evolution of human-pathogenic fungi: Phylogenies and species. In Molecular principles of fungal pathogenesis (ed. Heitman J, Filler SG, Edwards JE), pp. 113-132. ASM, Washington, DC.

Taylor JW. 2011. One fungus = one name: DNA and fungal nomenclature twenty years after PCR. IMA Fungus 2: 113-120.

Taylor JW, Berbee ML. 2006. Dating divergences in the Fungal Tree of Life: Review and new analyses. Mycologia 98: 838-849.

Taylor C, Gurr S. 2014. Fungal pathogenesis: Past, present and future. Fungal Biol Rev 28: 24-28.

Taylor JW, Turner E, Townsend JP, Dettman JR, Jacobson D. 2006. Eukaryotic microbes, species recognition and the geographic limits of species: Examples from the kingdom Fungi. Philos Trans R Soc Lond B Biol Sci 361: 1947-1963.

Teixeira MdM, Theodoro RC, Derengowski LdS, Nicola AM, Bagagli E, Felipe MS. 2013. Molecular and morphological data support the existence of a sexual cycle in species of the genus Paracoccidioides. Eukaryot Cell 12: 380-389.

Teixeira MdM, Theodoro RC, Oliveira FFMd, Machado GC, Hahn RC, Bagagli E, San-Blas G, Soares Felipe MS. 2014. Paracoccidioides lutzii sp. nov.: Biological and clinical implications. Med Mycol 52: 19-28.

Tsai IJ, Bensasson D, Burt A, Koufopanou V. 2008. Population genomics of the wild yeast Saccharomyces paradoxus: Quantifying the life cycle. Proc Natl Acad Sci 105: 49574962.

Villalta CF, Jacobson DJ, Taylor JW. 2009. Three new phylogenetic and biological Neurospora species: N. hispaniola N. metzenbergii and N. perkinsii. Mycologia 101: 777789.

Wapinski I, Pfeffer A, Friedman N, Regev A. 2007. Natural history and evolutionary principles of gene duplication in fungi. Nature 449: 54-61.

Whiston E, Wise HZ, Sharpton TJ, Jui G, Cole GT, Taylor JW. 2012. Comparative transcriptomics of the saprobic and parasitic growth phases in Coccidioides spp. Plos ONE 7: e41034.

White TJ, Bruns T, Lee S, Taylor J. 1990. Amplification and direct sequencing of fungal ribosomal RNA genes for phylogenetics. In PCR protocols: A guide to methods and applications (ed. Innis M, Gelfand D, Sninsky J, White T), pp. 315-322. Academic, Orlando, FL.

Xie J, Du H, Guan G, Tong Y, Kourkoumpetis TK, Zhang L, Bai FY, Huang G. 2012. $N$-acetylglucosamine induces white-to-opaque switching and mating in Candida tropicalis, providing new insights into adaptation and fungal sexual evolution. Eukaryot Cell 11: 773-782.

Xie J, Tao L, Nobile CJ, Tong Y, Guan G, Sun Y, Cao C, Hernday AD, Johnson AD, Zhang L, et al. 2013. Whiteopaque switching in natural MTLa $/ \alpha$ isolates of Candida albicans: Evolutionary implications for roles in host adaptation, pathogenesis, and sex. Plos Biol 11: e1001525. 


\section{$\&_{\mathrm{CSH}}^{\infty} \&$ Cold Spring Harbor

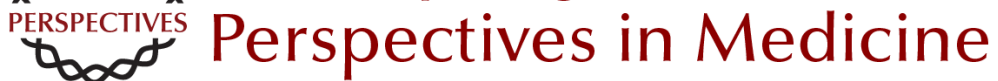

\section{Evolutionary Perspectives on Human Fungal Pathogens}

John W. Taylor

Cold Spring Harb Perspect Med 2015; doi: 10.1101/cshperspect.a019588 originally published online November 10, 2014

Subject Collection Human Fungal Pathogens

\section{Evolutionary Perspectives on Human Fungal Pathogens John W. Taylor}

Black Molds and Melanized Yeasts Pathogenic to Humans Anuradha Chowdhary, John Perfect and G. Sybren de Hoog

Fungal Pathogens: Survival and Replication within Macrophages

Andrew S. Gilbert, Robert T. Wheeler and Robin C. May

Innate Defense against Fungal Pathogens Rebecca A. Drummond, Sarah L. Gaffen, Amy G. Hise, et al.

Antifungal Pharmacokinetics and

Pharmacodynamics

Alexander J. Lepak and David R. Andes

Human Fungal Pathogens of Mucorales and Entomophthorales

Leonel Mendoza, Raquel Vilela, Kerstin Voelz, et al.

Functional Profiling of Human Fungal Pathogen Genomes

Alexi I. Goranov and Hiten D. Madhani

Aspergillus fumigatus and Related Species Janyce A. Sugui, Kyung J. Kwon-Chung, Praveen $R$. Juvvadi, et al.
Thermally Dimorphic Human Fungal Pathogens--

Polyphyletic Pathogens with a Convergent

Pathogenicity Trait

Anita Sil and Alex Andrianopoulos

Mechanisms of Antifungal Drug Resistance Leah E. Cowen, Dominique Sanglard, Susan J. Howard, et al.

Treatment Principles for Candida and Cryptococcus Laura C. Whitney and Tihana Bicanic

The Human Mycobiome Patrick C. Seed

Treatment Principles for the Management of Mold Infections

Dimitrios P. Kontoyiannis and Russell E. Lewis

Adaptive Immunity to Fungi Akash Verma, Marcel Wüthrich, George Deepe, et al.

The Candida Pathogenic Species Complex Siobhán A. Turner and Geraldine Butler

Fungal Morphogenesis Xiaorong Lin, J. Andrew Alspaugh, Haoping Liu, et al.

For additional articles in this collection, see http://perspectivesinmedicine.cshlp.org/cgi/collection/ 